\title{
COMPARTILHANDO SABERES E PRÁTICAS: O ESTÁGIO COMO EXPERIÊNCIA NA FORMAÇÃO INICIAL DE PROFESSORES DE EDUCAÇÃO INFANTIL
}

\author{
Renata Pavesi Cocito, Indira Aparecida Santana Aragão Favareto
}

Universidade Estadual Paulista - UNESP, Programa de Pós-Graduação em Educação. Presidente Prudente, SP. E-mail: renatapavesi@hotmail.com.

\section{RESUMO}

O artigo tem como enfoque uma experiência em Educação Infantil oriunda do estágio curricular supervisionado do curso Pedagogia da FCT/UNESP realizado em 2013. A trajetória de construção do estágio é descrita e tem como base ações integradoras iniciais como forma de estabelecer vínculos com a instituição onde o estágio será desenvolvido. Busca-se evidenciar o processo de formação inicial e a união entre teoria e prática, fatores preponderantes para a qualidade na formação do futuro professor de educação infantil. A vivência do grupo de estagiários traz como especificidade o trabalho com a organização do espaço da sala de referência do grupo de crianças em cantos temáticos.

Palavras-chave: Educação Infantil - formação inicial - estágio supervisionado - ações integradoras iniciais - organização do espaço.

\section{SHARING KNOWLEDGE AND PRACTICES : THE INTERNSHIP AS AN EXPERIENCE IN CHILDHOOD EDUCATION INITIAL TEACHER TRAINING}

\begin{abstract}
This paper has as its focus an experience in Childhood Education originated from the supervised traineeship of the Pedagogy course at FCT / UNESP, held in 2013. The trajectory of the traineeship construction is described and based on initial integrative actions as a way to bond with the institution where it was developed. The paper aims to highlight the initial formation process and the union between theory and practice as important factors for the quality of the future child educator formation. The trainees group experience has as its specificity the work with the organization of the reference room space with the group of children in thematic corners.

Keywords: childhood education - initial formation - supervised traineeship - initial integrative actions organization of space
\end{abstract}




\section{INTRODUÇÃO}

O presente artigo tem como alicerce as experiências vividas no ano de 2013, durante o estágio supervisionado em Educação Infantil com crianças na idade pré-escolar (4 - 5 anos) no Centro de Convivência Infantil "Chalezinho da Alegria" da FCT-UNESP de Presidente Prudente/SP. O estágio é parte da proposta curricular do quarto ano do curso de Pedagogia da mesma instituição.

Consideramos o estágio supervisionado uma possibilidade de contribuição concreta para a formação docente, pois se constitui como um processo em que o futuro professor irá participar e vivenciar momentos com as crianças e com docentes mais experientes. Essa relação colabora para compreenderem a essência e a complexidade da atuação profissional, bem como a responsabilidade incutida nos fazeres docentes cotidianos relacionados à criança pequena. Nessa perspectiva, Imbernón afirma:

Os futuros professores e professoras também devem estar preparados para entender as transformações que vão surgindo nos diferentes campos e para ser receptivos e abertos a concepções pluralistas, capazes de adequar suas atuações ás necessidades dos alunos e alunas em cada época e contexto. Para isso é necessário aplicar uma nova metodologia e, ao mesmo tempo, realizar uma pesquisa constante (o professor é capaz de gerar conhecimento pedagógico em sua prática) que faça mais do lhes proporcionar um amontoado de conhecimentos formais e formas culturais pré estabelecidas [...](IMBERNÓN, 2004,p.61-62).

O estágio se configura como possibilidade de relacionar teoria e prática de forma concreta. É um exercício de proximidade com a futura profissão, em que os graduandos terão acesso a um recorte da realidade e do cotidiano das vivências profissionais dos que já atuam na área. Sobre esta aproximação do aluno com o estágio, Pimenta e Lima colocam que:

O curso, o estágio, as aprendizagens das demais disciplinas e experiências e vivências dentro e fora da universidade ajudam a construir a identidade docente. O estágio, ao promover a presença do aluno estagiário no cotidiano da escola, abre espaço para a realidade e para a vida o trabalho do professor na sociedade. (PIMENTA e LIMA, 2012, p.67-68).

O entendimento da escola, como lugar da prática educativa, é o ponto de partida das instituições formadoras que têm como objetivo possibilitar aos futuros docentes compreender os saberes necessários para a sua atuação profissional. $O$ estágio permite aos professores, em processo de formação, a reflexão do trabalho docente, o envolvimento em experiências e diferentes situações que os auxiliem no conhecimento e compreensão dos saberes profissionais, considerando a pesquisa, o diálogo e relação entre saberes teóricos e práticos na constituição de uma formação sólida.

Tendo em vista alguns aspectos apresentados sobre a importância do estágio, consideramos o mesmo uma prática relevante para a construção do conhecimento profissional e de valorização da prática do professor. É no estágio que se permite vivenciar o contexto escolar e refletir sobre ele, problematizando questões e dialogando com situações diversas que ocorrem no interior da escola, considerando os professores como produtores de saberes, articulando os saberes teóricos e os saberes práticos e ressignificando-os, compreendendo a teoria como algo que nutre e dá consistência a ação docente.

Portanto, o papel da teoria é oferecer aos professores perspectivas de análise para compreender os conteúdos históricos, sociais, culturais, organizacionais e 
de si mesmos como profissionais, nos quais se da sua atividade docente, para neles, intervir, transformando-os. (PIMENTA, LIMA, 2012, p. 49).

O processo de formação inicial, além de proporcionar aspetos importantes ao exercício profissional docente e aproximar o futuro professor da realidade em que atuará através de experiências pedagógicas concretas, também é um momento no qual se deve centrar esforços para a reflexão e produção de saberes acadêmico-científicos dos futuros profissionais, atribuindo à formação um processo ainda mais dinâmico. Assim, partilhamos da concepção de Nóvoa $(1997$, p.18) que afirma: "Mais do que um lugar de aquisição de técnicas e conhecimentos, a formação de professores é o momento chave da socialização e da configuração profissional". Ou seja, a formação de professores precisa conceber aos profissionais a capacidade de refletir sua prática.

Assim sendo, este artigo tem como objetivo discutir a relevância do estágio curricular supervisionado na formação do professor de Educação Infantil como momento de aproximação com a prática docente e também como processo de aprendizagem que irá contribuir para a formação do profissional que irá atuar com crianças pequenas.

\section{A EXPERIÊNCIA DE ESTÁGIO: PROCESSOS METODOLÓGICOS E VIVÊNCIAS}

As vivências que serão partilhadas neste artigo ocorreram no ano de $2013 \mathrm{com}$ alunos do quarto ano do curso de Pedagogia da Faculdade de Ciências e Tecnologia- FCT Unesp de Presidente Prudente, o estágio curricular para educação infantil de 4 - 5 anos. 0 grupo de crianças para a realização do estágio era chamado "Pingo de Ouro", composto por 18 crianças com idade de 4 anos a 5 anos e 11 meses que, em sua maioria, frequentavam o período integral (até 10hs por dia na instituição). O grupo possuía 2 professoras de referência, ambas com formação em Pedagogia e especialização na área de educação, com 5 anos de atuação naquela instituição.

No primeiro momento do estágio os graduandos dedicaram-se a estudar concepções de infância, leis e documentos oficiais que normatizam os fazeres da Educação Infantil, conhecimentos sobre avaliação, a importância do brincar, o papel do professor na organização do ambiente, trabalho com famílias, a relação do cuidado e educação entre outros temas. Esse processo possibilitou o acesso à produção acadêmica e também compôs uma base para poderem atuar com as crianças de forma mais segura.

No segundo momento foi proposto, pela professora orientadora do estágio, a realização do estágio em grupos, e todos na mesma instituição. A ideia foi aceita e considerada diferenciada, pois nunca tinham realizado estágio em grupo até então.

Posteriormente foram feitas reuniões com o grupo de alunos/estagiários, professoras da instituição (onde seria desenvolvido o estágio) e com a orientadora do estágio. Essas ações iniciais têm como intuito estabelecer a aproximação dos estagiários com a instituição onde o estágio será desenvolvido, podendo chamá-las de ações integradoras iniciais. A história da instituição, sua rotina, a equipe de trabalho, a relação com os pais e comunidade, a organização, enfim, ter acesso a essas particularidades e especificidades são primordiais para que os estagiários possam saber onde serão inseridos e que o contexto da instituição seja compreendido. Acreditamos que o processo de aproximação torna o estagiário um membro a ser mais facilmente envolvido pela comunidade escolar, pois não é visto como alguém alheio àquela realidade. Essas ações integradoras iniciais foram fundamentais para a ambientação de alunos/estagiários e equipe escolar.

Foi proposto que o estágio fosse desenvolvido no Centro de Convivência Infantil da FCT/UNESP. Existem 15 Centros de Convivência Infantil espalhados em diversos campus da Unesp. 0 $\mathrm{CCl}$ onde desenvolvemos o estágio foi inaugurado em 1987 e, assim como os demais, surgiu em 
decorrência das necessidades e particularidades da época, focando o cuidar e o educar de crianças pequenas e edificando a Educação Infantil dentro da Universidade. Os CCls atendem crianças filhas ou dependentes legais de servidores técnico-administrativos, docentes e de alunos da FCT/UNESP.

Após definida a instituição, os estagiários foram divididos em grupos de estágios (o estágio foi desenvolvido em grupo de cerca de 4 ou 5 alunos/estagiários). 0 estágio foi constituído por 3 etapas: processo de observação, discussão do que foi observado e percebido sob orientação da professora responsável pelo estágio e definição de uma temática para ser trabalhada como proposta de intervenção.

Inicialmente, foi organizado um cronograma para a realização das observações com a participação de todos os envolvidos no processo. Cada grupo teve um tempo para iniciar suas observações e também foram mantidos diálogos semanais com a professora orientadora do estágio. Foi um momento rico, pois os estagiários participavam da rotina da instituição junto às crianças, professoras e equipe escolar.

Após as observações, foram realizadas reuniões junto à professora orientadora. Cada grupo expôs suas experiências decorrentes do campo de observação e, com base nas vivências, definiram as propostas/temáticas que seriam desenvolvidas nas intervenções. Cada grupo de estagiários elegeu uma temática para ser trabalhada.

\section{RESULTADOS}

Um dos grupos identificou a necessidade de trabalhar a organização dos espaços. A definição da proposta de intervenção tem sua gênese na percepção das necessidades do grupo de crianças e na compreensão do grupo de estagiárias acerca da relevância do espaço/ambientes para o cotidiano da Educação Infantil.

Naquele momento foram identificadas, na prática docente da instituição, tentativas de organizar as salas, utilizando a proposta de cantos temáticos. Era possível perceber através da forma como o mobiliário estava disposto no espaço da sala e também em conversas com as educadoras responsáveis pelo grupo de crianças. Oliveira (2011) nos oferece a compreensão do que são os cantos/cantos temáticos/cantinhos e a sua relevância para a organização do espaço bem como para o desenvolvimento infantil:

Tem sido muito valorizada a organização das áreas de atividades diversificadas, os "cantinhos" - da casinha, do médico ou dentista, do supermercado, da leitura, do descanso -, que permitem a cada criança interagir com um pequeno número de companheiros, possibilitando-lhe melhor coordenação de suas ações e a criação de um enredo comum na brincadeira, o que aumenta a troca e o aperfeiçoamento da linguagem. (...) Entretidas, as crianças produzem conhecimentos e significações partilhadas, num clima de tranqüilidade e concentração. Essas áreas podem concretizar determinados cenários favoráveis à brincadeira simbólica ou a atividades exploratórias ou expressivas. (OLIVEIRA, 2011, p.199-200)

Observando o espaço da sala das crianças, foi considerado que faltavam elementos para desenhar essa prática, de organização do espaço em cantos, com mais propriedade na instituição. Em reuniões individuais com a orientadora de estágio, foram realizadas leituras sobre a temática e o planejamento de uma proposta de intervenção também foi apresentado e discutido com as professoras da instituição responsáveis pelo grupo de crianças. 
Os cantos temáticos são uma forma de tornar um espaço escolar mais significativo para as crianças, pois ampliam as possibilidades de interação entre as mesmas e com os materiais existentes nos espaços da sala. Ainda contribuem para que diferentes habilidades infantis sejam desenvolvidas cotidianamente, de forma lúdica, prazerosa e espontânea; alicerçadas por uma prática docente cuidadosa, de observação e escuta das crianças.

Assim, tendo como ideia central o incremento da estruturação dos espaços com base no conceito de cantos temáticos no campo de estágio, graduandos e professoras de Educação Infantil estruturaram os seguintes cantos: artes plásticas, supermercado, jogos e leitura. No decorrer da intervenção, os estagiários perceberam que o canto mais frequentado era o supermercado, foi quando decidiram ampliar esse canto para que mais crianças pudessem brincar juntas, em um grupo maior, visto que o canto inicialmente projetado comportava até cinco crianças.

A percepção acerca das preferências das crianças e a identificação com o espaço é importante para se desenvolver uma prática em harmonia com os desejos da criança, para que tenha relação com o que querem e precisam naquele momento. A observação, a escuta e a leitura das relações estabelecidas entre a criança e o espaço que esta ocupando é fundamental para que sua organização seja significativa como nos aponta Barbosa: "a organização do ambiente traduz uma maneira de compreender a infância, de entender seu desenvolvimento e o papel da educação e do educador" (2006, p.122). O ambiente deve ser organizado para que as crianças possam interagir entre seus pares, com os adultos, desenvolver aprendizagens e, com isso, assegurar o desenvolvimento cognitivo, afetivo e social.

\section{DISCUSSÃO}

Portanto, considerar a estruturação do espaço, com enfoque pedagógico, é preponderante. Pensar nesse espaço como um aliado para o processo de desenvolvimento da aprendizagem da criança ou ainda tê-lo como outro educador, como nos aponta alguns autores como Edwards, Gandini e Formam (1999) e Kinney e Wharton (2009), por exemplo, é algo que deve ser pensado pelos profissionais de educação e, por conseguinte, fazer parte das vivências educacionais com crianças pequenas. Nesta mesma perspectiva Edwards, Gandini e Forman (1999, p. 157) revelam que:

A fim de agir como um educador para a criança, o ambiente precisa ser flexível; deve passar por uma modificação frequente pelas crianças e pelos professores a fim de permanecer atualizado e sensível as suas necessidades de serem protagonistas na construção de seu conhecimento. Tudo o que cerca as pessoas na escola e o que usam - os objetos, os materiais e as estruturas não são vistos como elementos cognitivos passivos, mas, ao contrário, como elementos que condicionam e são condicionados pelas ações dos indivíduos que agem nela.

Consideramos que a intencionalidade dos estagiários e a forma como o trabalho das professoras vinha sendo delineado no cotidiano da instituição, tornaram-se práticas complementares, exercitou os saberes adquiridos no curso de Pedagogia e o outro teve a possibilidade de incrementar sua prática cotidiana e estruturar seu fazer relacionado à organização dos espaços em "cantos".

Desta forma, ao final do período de estágio, observamos a necessidade de preparar os espaços com cuidado para as crianças, de forma que o seu uso seja otimizado e que se tornem um espaço significativo para elas, aconchegante, estimulantes, desafiador. Um espaço onde as crianças queiram estar e onde possam passar momentos agradáveis durante a longa permanência na 
instituição. As discussões e orientações que aconteceram durante o processo de estágio foram de suma importância para a percepção acerca das necessidades das crianças e do enfoque percebido e direcionado à organização dos espaços na Educação Infantil. Criou-se um elo entre o saber empírico e o saber científico, assim "nessa perspectiva, a pesquisa é componente essencial das práticas de estágio, apontando novas possibilidades de ensinar e aprender a profissão docente [...]" (PIMENTA, LIMA, 2012, p.114).

Como última ação do processo de estágio, todas as intervenções dos grupos de estágio foram publicadas no blog do Centro de Convivência Infantil e divulgado para os pais, responsáveis e comunidade em geral, como forma de mostrar o resultado de um longo processo coletivo de trabalho, e ainda estabelecer conexão entre todos os envolvidos no cotidiano escolar, evidenciando que a Educação Infantil também é espaço para ensino, pesquisa e extensão, para o desenvolvimento de saberes e para a formação de profissionais.

\section{CONCLUSÃO}

O estágio se constitui em uma relação entre escola e universidade, entre o campo das ideias e o campo de ação, tem como compromisso oferecer indícios básicos para a formação inicial de professores e dar a eles condições básicas para o exercício do magistério. Dessa maneira, o estágio necessita ser um momento de pesquisa e reflexão da formação e da prática docente, é parte da construção do profissional professor.

A percepção e a decisão de atrelar a temática da organização dos espaços em "cantos" com a proposta de intervenção do estágio foi assertiva visto que, reforçou para as professoras da instituição que os espaços estão entre uma das preocupações do fazer docente e que deve ser pensado e planejado. É gratificante perceber que foi possível dar contribuições importantes para os profissionais da instituição onde o estágio foi desenvolvido. Propiciou ainda uma vivência para o grupo de estagiárias que poderá ser amadurecida e colocada em prática quando em atuação em sala de aula.

Destacamos, com isso, a importância do estágio para a formação inicial, onde pudemos compartilhar, com os demais graduandos, professora orientadora, educadoras infantis, equipe escolar, crianças e famílias, a rotina de uma instituição de Educação Infantil, buscando compreender seus desafios e possibilidades. O estágio proporcionou a interlocução teoria e prática, permitindo vivenciar experiências significativas que servirão de base no momento do exercício do futuro professor.

\section{REFERÊNCIAS}

BARBOSA, M. C .S. Por Amor e por Força: Rotinas na Educação Infantil. Porto Alegre: Artmed, 2006.

EDWARDS, C.; GANDINI, L.; FORMAN, G. As cem linguagens da criança: a abordagem de Reggio Emilia na educação da primeira infância/ tradução Dayse Batista. Porto Alegre: Artmed, 1999.

IMBERNÓN, F. A Formação permanente do professor In: Formação docente profissional. Formar-se para a mudança e a incerteza. São Paulo: Cortez, 2004. p.48-56.

KINNEY, L.; WHARTON, P. Tornando visível a aprendizagem das crianças/ tradução Magda França Lopes. Porto Alegre: Artmed, 2009. 
NÓVOA, A. Formação de professores e profissão docente 13-33 In: NÓVOA, A. (org) Os professores e a sua formação. Lisboa, Dom Quixote, 1997, p. 13-33.

OLIVEIRA, Z. R.Os ambientes de aprendizagem como recursos pedagógicos. In: OLIVEIRA, Zilma Ramos de. Educação Infantil: fundamentos e métodos.Cortez: São Paulo, 2011.

PIMENTA, S. G.; LIMA, M. S. L. Estágio e Docência. 7. Ed. São Paulo: Cortez, 2012. 